\title{
Modeling Experimental Design for Photo-Fenton Degradation of Methomyl
}

\author{
Abdelhadi Abaamrane $^{1,2^{*}}$, Samir Qourzal ${ }^{2}$, Saïd Mançour Billah ${ }^{1}$, Ali Assabbane ${ }^{2}$, Yhya Ait-Ichou ${ }^{2}$ \\ ${ }^{1}$ Laboratoire de Génie des Procédés, Département de Chimie, Faculté des Sciences, \\ Université Ibn Zohr, Agadir, Morocco \\ ${ }^{2}$ Equipe de Matériaux, Photocatalyse et Environnement, Département de Chimie, Faculté des Sciences, \\ Université Ibn Zohr, Agadir, Morocco \\ Email: *abd.abaamrane@yahoo.fr
}

Received August 27, 2012; revised September 30, 2012; accepted October 10, 2012

\begin{abstract}
Modeling experimental design was used to study the main effects and the interaction effects between operational parameters in the photocatalytic degradation of pesticide methomyl. The important parameters which affect the removal efficiency of methomyl such as concentration of $\mathrm{Fe}\left(\mathrm{NO}_{3}\right)_{3}$, concentration of $\mathrm{H}_{2} \mathrm{O}_{2}$, initial concentration of the pesticide and $\mathrm{pH}$. The parameters were coded as $x_{1}, x_{2}, x_{3}$ and $x_{4}$, consecutively, and were investigated at two levels $(-1$ and +1$)$. The effects of individual variables and their interaction effects for dependent variables, namely, photocatalytic degradation efficiency (\%) were determined. From the statistical analysis, the most effective parameters in the photocatalytic degradation efficiency were initial concentrations of the methomyl and $\mathrm{Fe}\left(\mathrm{NO}_{3}\right)_{3}$. The interaction between initial concentration of the pesticide and $\mathrm{Fe}\left(\mathrm{NO}_{3}\right)_{3}$ was the most influencing interaction. The optimum conditions that were obtained for the photocatalytic degradation of methomyl were: minimum quantity of contaminant: $6 \times 10^{-5} \mathrm{~mol} \cdot \mathrm{L}^{-1}$, maximum quantity of $\mathrm{Fe}\left(\mathrm{NO}_{3}\right)_{3}: 5 \times 10^{-4} \mathrm{~mol} \cdot \mathrm{L}^{-1}$, initial $\mathrm{pH}$ of the solution: 3 and maximum quantity $\mathrm{H}_{2} \mathrm{O}_{2}: 10^{-2}$ $\mathrm{mol} \cdot \mathrm{L}^{-1}$.
\end{abstract}

Keywords: Methomyl; Photocatalytic Degradation; Response Surface Methodology (RSM); Full Factorial Design

\section{Introduction}

Pesticides are commonly used worldwide to face the need for increasing and improving agricultural production $[1,2]$. The detection of pesticides in storm and wastewater effluent is reported to be a major obstacle as regards wide ranging acceptance of water recycling. Furthermore, their variety, toxicity and persistence can directly impact the ecosystem and threaten humans through contamination of drinking water supplies (surface and ground water).

Methomyl is an oxime carbamate insecticide (Figure 1). It is produced by reacting S-methyl-N-hydroxylthio acetamidate (MHTA) in methylene chloride with gaseous methyl isocyanate at $30^{\circ} \mathrm{C}-35^{\circ} \mathrm{C}$. Methomyl is highly soluble in water $\left(57.9 \mathrm{~g} \cdot \mathrm{L}^{-1}\right)$ [3]. It has a low sorption affinity to soil and can therefore easily cause groundwater contamination in agricultural areas.

Methomyl is effective in two ways: 1) as a "contact insecticide" because it kills target insects upon direct contact; and 2) as a "systemic insecticide" because of its capability to cause overall "systemic" poisoning in target insects, after it is absorbed and transported throughout

*Corresponding author. the pests that feed on treated plants. This insecticide is mainly used in Morocco on a wide range of tomato crops. However, it has been classified as a very toxic and hazardous pesticide [4].

Recently, chemical treatment methods, based on the generation of hydroxyl radicals $\left(\mathrm{OH}^{*}\right)$, known as Advanced Oxidation Processes (AOPs), due to their efficiency in oxidizing a great variety of organic contaminants [5-9].

The Fenton treatments are the requirement of $\mathrm{H}_{2} \mathrm{O}_{2}$, $\mathrm{Fe}^{2+}$ salts and $\mathrm{pH}$ adjustment (mostly acidic). With the additions of $\mathrm{H}_{2} \mathrm{O}_{2}$ and $\mathrm{Fe}^{2+}$ salts, highly reactive and unselective oxidants are produced as shown in Equation (1) that leads to the formation of less powerful hydroperoxyl

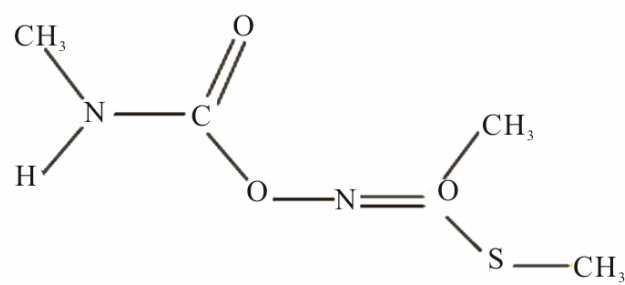

Figure 1. Chemical structure of methomyl. 
radical $\left(\mathrm{HO}_{2}^{\cdot}\right)$ as per Equation (2) $[10,11]$.

$$
\begin{gathered}
\mathrm{Fe}^{2+}+\mathrm{H}_{2} \mathrm{O}_{2} \rightarrow \mathrm{Fe}^{3+}+\mathrm{OH}^{\cdot}+\mathrm{OH}^{-} \\
\mathrm{Fe}^{3+}+\mathrm{H}_{2} \mathrm{O}_{2} \rightarrow \mathrm{Fe}^{2+}+\mathrm{HO}_{2}^{\cdot}+\mathrm{H}^{+}
\end{gathered}
$$

In order to overcome the sludge problem and enhance the Fenton treatment, the photo-Fenton process was developed by introducing a UV light to the Fenton process.

In the presence of $\mathrm{UV}$-irradiation, the $\mathrm{Fe}^{3+}$ complex formed in Equation (1) can be photo reduced to $\mathrm{Fe}^{2+}$. This could facilitate the reaction of photo reduced $\mathrm{Fe}^{2+}$ with more $\mathrm{H}_{2} \mathrm{O}_{2}$ molecules, which produce new $\mathrm{OH}^{*}$ (Equation (3)) and form a Fenton reaction cycle [12]. This cycle is useful for the progress of the Fenton treatment with no continuous addition of $\mathrm{Fe}^{2+}$ and devoid of ferric hydroxide sludge. Moreover, two $\mathrm{OH}^{*}$ can be produced from hydrogen peroxide under the UV-irradiation as shown in Equation (4) $[13,14]$.

$$
\begin{aligned}
& \mathrm{FeOH}^{2+}+\mathrm{h} v \rightarrow \mathrm{Fe}^{2+}+\mathrm{OH}^{\cdot} \\
& \mathrm{H}_{2} \mathrm{O}_{2}+\mathrm{h} v \rightarrow 2 \mathrm{OH}^{\cdot}
\end{aligned}
$$

In conventional AOPs methods, the experiments are usually conducted by varying some studied parameters while keeping others constant. To avoid repeating this process for all influential parameters, factorial design $[15,16]$ is an experimental strategy that allows the simultaneous manipulation of many factors and possible synergistic and antagonistic interactions between them that are determined. In addition, system optimization can be attained performing a smaller number of experiments than that needed for univariate techniques resulting in lower reagent consumption and considerably less laboratory work.

The Response Surface Methodology (RSM) also is an efficient experimental strategy for determining the optimal conditions. This method is a collection of statistical and mathematical techniques used for development, improvement, and optimization of certain processes in which a response of interest is affected by several process variables and the objective is to optimize this response. RSM was applied to AOPs to design and formulate new processes and products. The results have been satisfactory in studies that involve the application of factorial design in the photocatalytic degradation of organic compounds [17-20].

The objective of this study is to determine the optimal experimental conditions for methomyl degradation in photo-Fenton treatment combining $\mathrm{H}_{2} \mathrm{O}_{2} / \mathrm{Fe}^{2+} / \mathrm{UV}$ using RSM, and to examine both single and combined effects among independent variables of $\mathrm{Fe}\left(\mathrm{NO}_{3}\right)_{3}, \mathrm{H}_{2} \mathrm{O}_{2}$, methomyl concentration and $\mathrm{pH}$.

\section{Experimental}

\subsection{Reagents}

De-ionized water is used throughout this study. Metho- myl $\left(\mathrm{C}_{5} \mathrm{H}_{10} \mathrm{~N}_{2} \mathrm{O}_{2} \mathrm{~S}\right)$ is purchased from Merck Chemical Company at highest purity $(99.9 \%)$. Ferric nitrate nonahydrate $\left(\mathrm{Fe}\left(\mathrm{NO}_{3}\right)_{3} \cdot 9 \mathrm{H}_{2} \mathrm{O}\right)$ is provided by Prolabo. Hydrogen peroxide solution $(35 \%, \mathrm{v} / \mathrm{v})$ in stable form is provided by Panreac. The $\mathrm{pH}$ of the pesticide solution is adjusted by using $\mathrm{H}_{2} \mathrm{SO}_{4}$ or $\mathrm{NaOH}$ (Merck).

\subsection{Experimental Apparatus}

All photo-Fenton experiments were performed in a well stirred, batch, cylindrical photoreactor with a total volume of $500 \mathrm{~mL}$ (Figure 2). The reactor is made of glass and does not contain any metal parts. At the top, the reactor has inlets for feeding reactants, and ports for measuring temperature and withdrawing samples. The reactor was exposed to a luminous source composed of a medium pressure mercury-lamp (Philips HPK, $125 \mathrm{~W}$ ) which emitted a maximum radiation at $365 \mathrm{~nm}$, placed in axial position inside a quartz sleeve. The agitation was assured by means of a magnetic stirrer placed at the reactor base.

\subsection{Procedures and Analysis}

Preliminary experiments were carried out to screen the appropriate parameters and to determine the experimental domain. From these experiments, concentration of $\mathrm{Fe}\left(\mathrm{NO}_{3}\right)_{3}$, concentration of $\mathrm{H}_{2} \mathrm{O}_{2}$, initial concentration of the pesticide and $\mathrm{pH}$ were the factors involved in this study. Levels of the factors studied are shown in Table 1.

A two-level-four-factor $\left(2^{4}\right)$ full factorial experiment was designed to observe the effect of the parameters influencing photocatalytic degradation of pesticide methomyl.

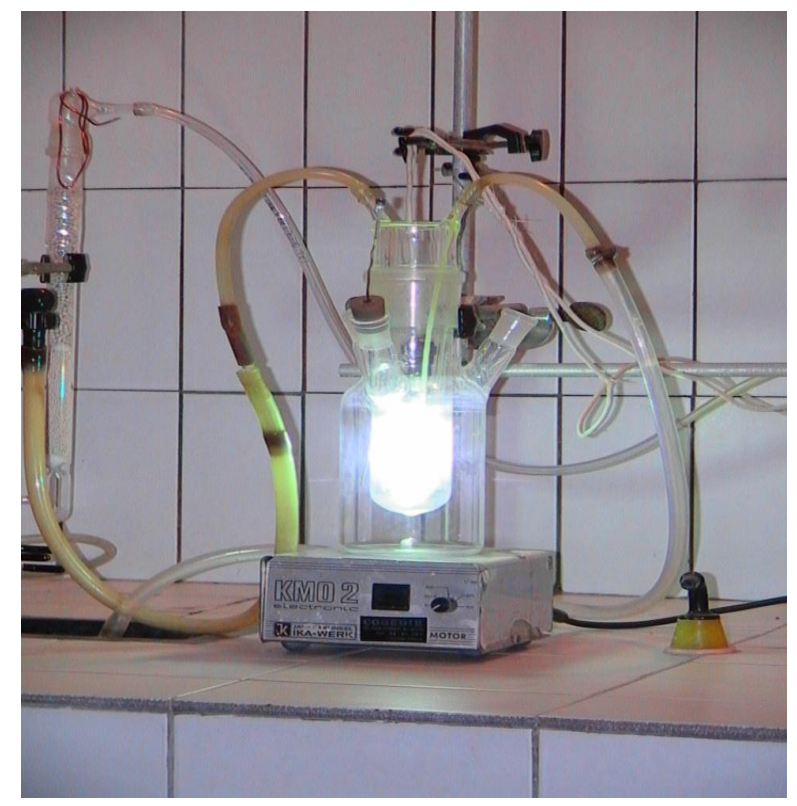

Figure 2. Schematic diagram of the photocatalytic reactor. 
Table 1. Factors and levels used in the $2^{4}$ factorial design study.

\begin{tabular}{lccc}
\hline \multicolumn{1}{c}{ Parameter name } & Code & Low $(\mathbf{- 1 )}$ & High (+1) \\
\hline $\begin{array}{l}\mathrm{Fe}\left(\mathrm{NO}_{3}\right)_{3} \text { concentration } \\
\left(\mathrm{mol} \cdot \mathrm{L}^{-1}\right)\end{array}$ & $x_{1}$ & $10^{-4}$ & $5 \times 10^{-4}$ \\
$\begin{array}{l}\mathrm{H}_{2} \mathrm{O}_{2} \text { concentration } \\
\left(\mathrm{mol} \cdot \mathrm{L}^{-1}\right)\end{array}$ & $x_{2}$ & $10^{-3}$ & $10^{-2}$ \\
$\begin{array}{l}\mathrm{Methomyl} \mathrm{concentration} \\
\left(\mathrm{mol} \cdot \mathrm{L}^{-1}\right)\end{array}$ & $x_{3}$ & $6 \times 10^{-5}$ & $1.23 \times 10^{-4}$ \\
Initial $\mathrm{pH}$ value & $x_{4}$ & 3 & 5.4 \\
\hline
\end{tabular}

The photocatalytic efficiency was determined by using the following equation:

$$
Y(\%)=\frac{\mathrm{A}_{0}-\mathrm{A}_{r}}{\mathrm{~A}_{0}} \times 100
$$

where $Y$ is the photocatalytic efficiency (\%), $\mathrm{A}_{0}$ and $\mathrm{A}_{r}$ both in $\left(\mathrm{mol} \cdot \mathrm{L}^{-1}\right)$ are, respectively, the initial and residual concentrations of methomyl in solution.

In this research, a $2^{4}$ full factorial design was employed to fit a second-order polynomial model. The general equation of the second degree polynomial is stated as follows:

$$
Y=a_{0}+\sum a_{i} x_{i}+\sum a_{i j} x_{i} x_{j}+\varepsilon
$$

where $Y$ is the dependent variable (response variable) to be modelled, $x_{i}$ and $x_{j}$ are the independent variables (factors), $a_{0}, a_{i}, a_{i j}$ are regression coefficients and $\varepsilon$ is the error.

The analysis of results was performed with statistical and graphical analysis software (Design-Expert 8.0.1, by Stat-Ease Inc., USA). This software was used for regression analysis of the data obtained and to estimate the coefficient of regression equation. ANOVA (analysis of variance) which is statistical testing of the model in the form of linear term, squared term and interaction term was also utilized to test the significance of each term in the equation and goodness of fit of the regression model obtained [21]. This response surface model was also used to predict the result by isoresponse contour plots and three dimensional surface plots. Contour plot is the projection of the response surface as a two dimensional plane where as 3D surface plots is the projection of the response surface in a three dimensional plane [22].

\section{Results and Discussions}

\subsection{Experimental Results and Its Evaluation}

In the development of a degradation process, the number of the necessary empirical experiments to determine the process conditions can be reduced by using a practical approach that exploits the known effects of system parameters on the degradation behaviour of methomyl. To analyze the effect of changes in parameters involved and to model the dimensional accuracy for various degradation conditions and to better evaluate the interaction between the parameters, the full factorial experimental design and response surface methodology was implemented. The adequacy of the model is also tested by the method of analysis of variance (ANOVA) and additional degradation experiments [23]. This factorial design results in sixteen tests with all possible combinations of $x_{1}, x_{2}, x_{3}$ and $x_{4}$. The methomyl removal efficiency $(Y)$ after 15 min light irradiation as shown in Table 2.

A first-order model with all possible interactions was chosen to fit the experimental:

$$
\begin{aligned}
Y & =a_{0}+a_{1} x_{1}+a_{2} x_{2}+a_{3} x_{3}+a_{4} x_{4} \\
& +a_{12} x_{12}+a_{13} x_{13}+a_{23} x_{23}+a_{14} x_{14} \\
& +a_{24} x_{24}+a_{34} x_{34}+a_{123} x_{123}+a_{124} x_{124} \\
& +a_{134} x_{134}+a_{234} x_{234}+a_{1234} x_{1234}
\end{aligned}
$$

The coefficients of the first-order polynomial equation corresponding to each dependent variable were developed by multiple regression analysis using the DesignExpert 8.0.1 statistical software.

Data analysis using the Design-Expert 8.0.1 statistical software at $95 \%$ of confidence level permitted to obtain a semi-empirical expression which consists of 12 statistically significant coefficients having absolute value greater than zero, with a probability of $95 \%(\mathrm{p}<0.05)$ :

Table 2. Experimental results of 24 factorial design for the photo-Fenton degradation of methomyl.

\begin{tabular}{ccccccc}
\hline Experiment & $x_{1}$ & $x_{2}$ & $x_{3}$ & $x_{4}$ & $\begin{array}{c}Y \\
\text { (Experimental) }\end{array}$ & $\begin{array}{c}Y \\
\text { (Predicted) }\end{array}$ \\
\hline 1 & -1 & -1 & -1 & -1 & 98.94 & 98.99 \\
2 & +1 & -1 & -1 & -1 & 100 & 99.95 \\
3 & -1 & +1 & -1 & -1 & 99.37 & 99.32 \\
4 & +1 & +1 & -1 & -1 & 100 & 100.05 \\
5 & -1 & -1 & +1 & -1 & 66.62 & 66.67 \\
6 & +1 & -1 & +1 & -1 & 96.96 & 96.91 \\
7 & -1 & +1 & +1 & -1 & 73.68 & 73.63 \\
8 & +1 & +1 & +1 & -1 & 97.99 & 98.04 \\
9 & -1 & -1 & -1 & +1 & 96.68 & 96.63 \\
10 & +1 & -1 & -1 & +1 & 100 & 100.05 \\
11 & -1 & +1 & -1 & +1 & 98.27 & 98.32 \\
12 & +1 & +1 & -1 & +1 & 100 & 99.95 \\
13 & -1 & -1 & +1 & +1 & 58.33 & 58.28 \\
14 & +1 & -1 & +1 & +1 & 94.94 & 94.99 \\
15 & -1 & +1 & +1 & +1 & 63.10 & 63.15 \\
16 & +1 & +1 & +1 & +1 & 95.60 & 95.55 \\
\hline
\end{tabular}




$$
\begin{aligned}
Y= & 90.03+8.16 x_{1}+0.97 x_{2}-9.13 x_{3}-1.66 x_{4} \\
& -0.76 x_{12}+7.31 x_{13}+0.72 x_{23}+1.11 x_{14}-1.24 x_{34} \\
& -0.51 x_{123}+0.69 x_{134}
\end{aligned}
$$

The fit of the model was further checked by the coefficient of determination $R^{2}$. The $R^{2}$ value is always between 0 and 1 . The closer the $R^{2}$ value is to 1 , the better the model predicts the response [24]. The statistically significant variables at $95 \%$ level of confidence were tested using analysis of variance (ANOVA) and were: $R^{2}=$ $0.9995, x^{2}=183.07$ and $\mathrm{F}=11.103 \times 10^{-6}$; where $R^{2}$ is the correlation coefficient, $x^{2}$ the sum of quadratic residuals and $\mathrm{F}$ is the F-value. The coefficients of multiple determinations, $R^{2}$, representing the fit of the models to the experimental data was 0.9995 indicating that $99.95 \%$ of the variability in the response could be explained by the model.

A graph of the actual response values versus the predicted response values are shown in Figure 3. Actual values are the experimental response data for a particular run, and the predicted values were evaluated from the model and generated by using the approximating function. As can be seen in the Figure 3, the experimental results are in good agreement with the values calculated by the first-order polynomial equation.

Figure 4 shows the residual value and the order of the corresponding observations. This plot can be helpful to a designed experiment in which the runs are not randomized. For residual activity data, the residuals appear to be randomly scattered about zero. No evidence exists that the regression terms are correlated with one another.

\subsection{Analysis of RSM}

The 3D response surface, which is a three dimensional graphic representation was used to determine the individual and cumulative effect of the variable and the mutual interaction between the variable and the dependent

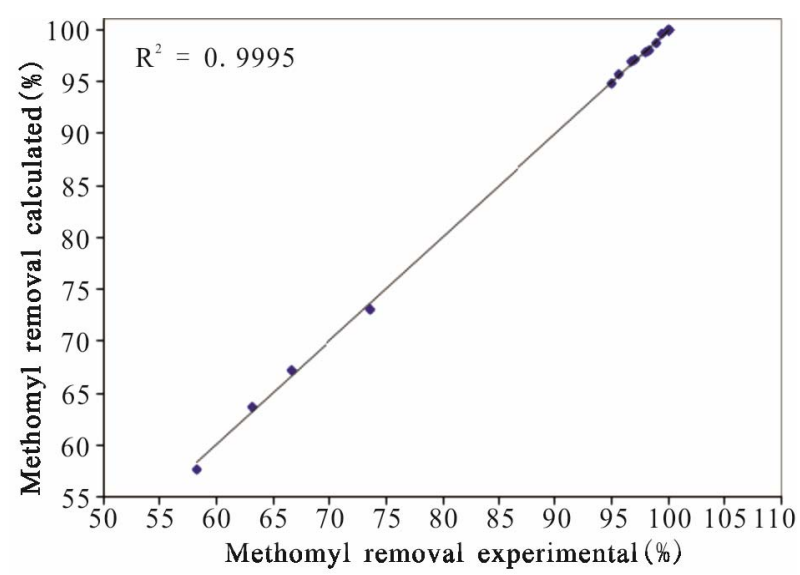

Figure 3. Experimental and calculated values for methomyl removal.

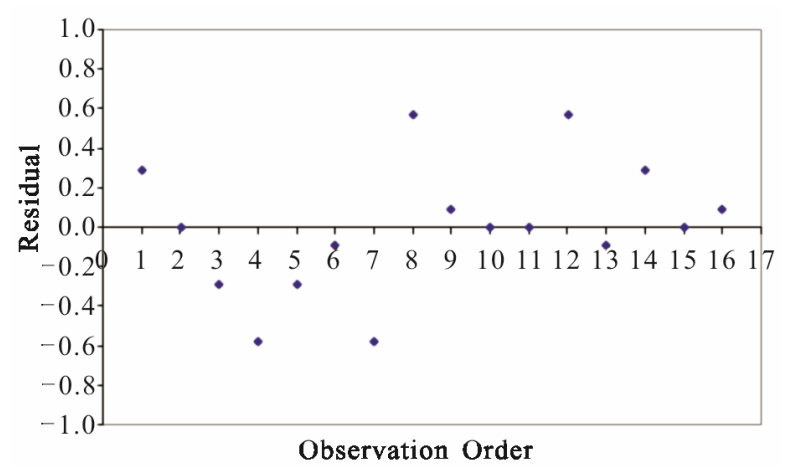

Figure 4. The residual value plot of photo-Fenton degradation of methomyl.

variable. The response surface analyzes the geometric nature of the surface, the maxima and minima of the response and the significance of the coefficients of the canonical equation. The polynomial response surface model obtained may be maximized or minimized to obtain the optimum points. Whereas a contour plot is a graphical technique for representing a three dimensional surface by plotting constant $z$-slices called contours, on a two dimensional format. That is, given a value for $z$, lines are drawn for connecting the $(x, y)$ coordinates where that $z$ value occurs [25].

To investigate the individual and interactive effect of these four factors on the methomyl removal efficiency, three dimensional and contour plots were drawn with the help of Design-Expert 8.0.1 statistical software and the inferences thus obtained are discussed below.

The response surface graphs of methomyl removal are shown in Figures 5-8. It can be shown from Figures 5-8 that a strong interaction exists among $\mathrm{Fe}\left(\mathrm{NO}_{3}\right)_{3}$ concentration, initial methomyl concentration, $\mathrm{H}_{2} \mathrm{O}_{2}$ concentration and $\mathrm{pH}$.

Figure 5 shows the effect of $\mathrm{Fe}\left(\mathrm{NO}_{3}\right)_{3}$ concentration and $\mathrm{H}_{2} \mathrm{O}_{2}$ concentration on methomyl removal efficiency. The response surface of methomyl removal efficiency gradually increased with increasing $\mathrm{H}_{2} \mathrm{O}_{2}$ concentration from $10^{-3} \mathrm{~mol} \cdot \mathrm{L}^{-1}$ to $10^{-2} \mathrm{~mol} \cdot \mathrm{L}^{-1}$. The maximum value of photo-Fenton degradation determined was $98 \%$ at $\mathrm{Fe}\left(\mathrm{NO}_{3}\right)_{3} 5 \times 10^{-4} \mathrm{~mol} \cdot \mathrm{L}^{-1}$ and $10^{-2} \mathrm{~mol} \cdot \mathrm{L}^{-1} \mathrm{H}_{2} \mathrm{O}_{2}$.

This can be explained by the effect of the additionally produced hydroxyl radicals. This may be due to recombination of hydroxyl radicals and also hydroxyl radicals reaction with $\mathrm{H}_{2} \mathrm{O}_{2}$, contributing to the $\mathrm{OH}^{\bullet}$ scavenging capacity (Equations (9)-(11)) [4].

$$
\begin{aligned}
& \mathrm{H}_{2} \mathrm{O}_{2}+\mathrm{OH}^{\cdot} \rightarrow \mathrm{H}_{2} \mathrm{O}+\mathrm{HO}_{2}^{-} \\
& \mathrm{HO}_{2}^{-}+\mathrm{OH}^{\cdot} \rightarrow \mathrm{H}_{2} \mathrm{O}+\mathrm{O}_{2} \\
& \mathrm{OH}^{\cdot}+\mathrm{OH}^{\cdot} \rightarrow \mathrm{H}_{2} \mathrm{O}_{2}
\end{aligned}
$$

Figure 6 shows the effect of $\mathrm{Fe}\left(\mathrm{NO}_{3}\right)_{3}$ concentration and initial methomyl concentration on methomyl removal 

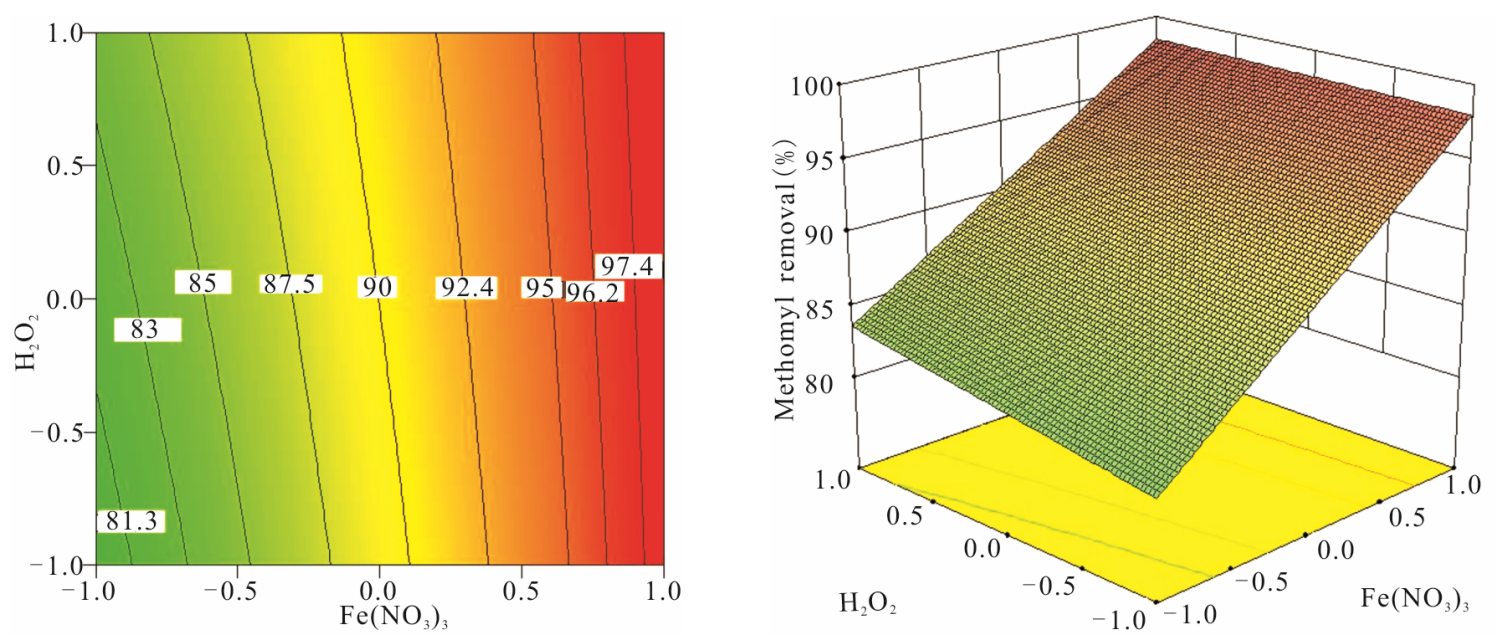

Figure 5. The response surface and contour plot as a function of $\mathrm{Fe}\left(\mathrm{NO}_{3}\right)_{3}$ dosage rate and $\mathrm{H}_{2} \mathrm{O}_{2}$ dosage of methomyl removal at $15 \mathrm{~min}$.
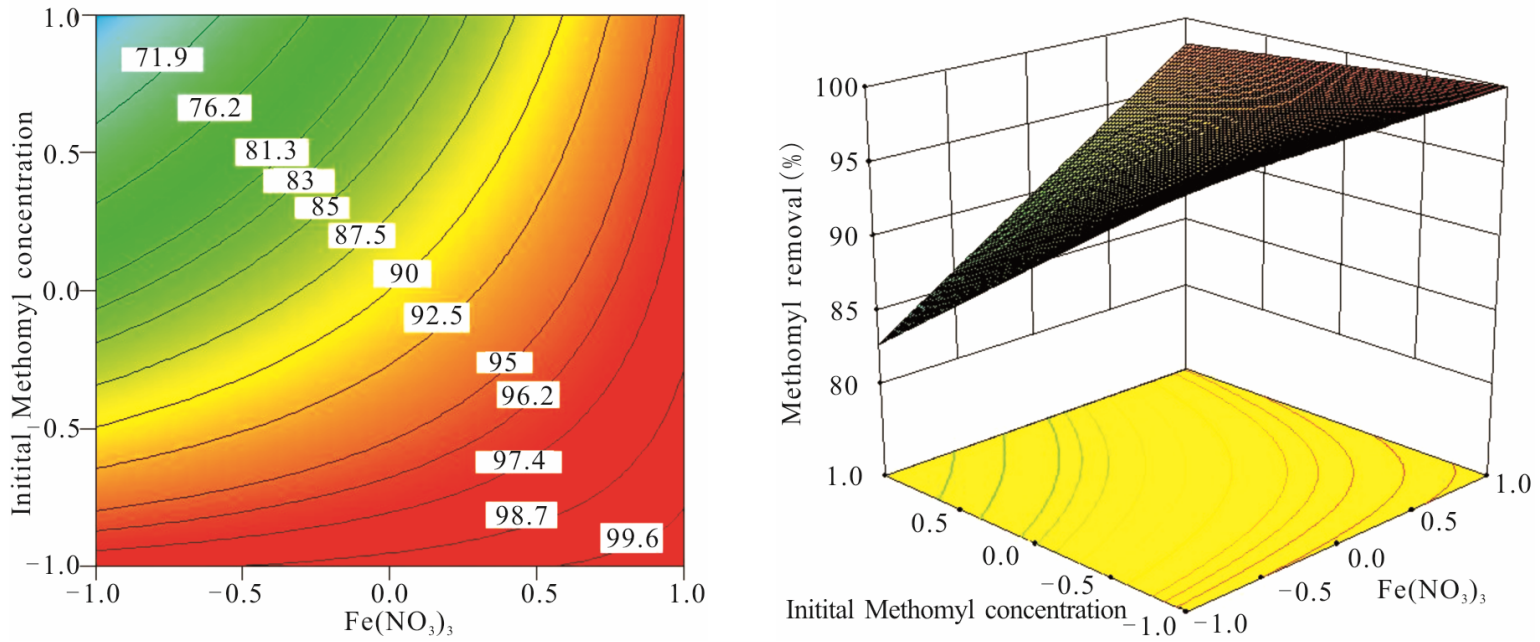

Figure 6. The response surface and contour plot as a function of $\mathrm{Fe}\left(\mathrm{NO}_{3}\right)_{3}$ dosage rate and initial methomyl concentration of methomyl removal at $\mathbf{1 5} \mathrm{min}$.
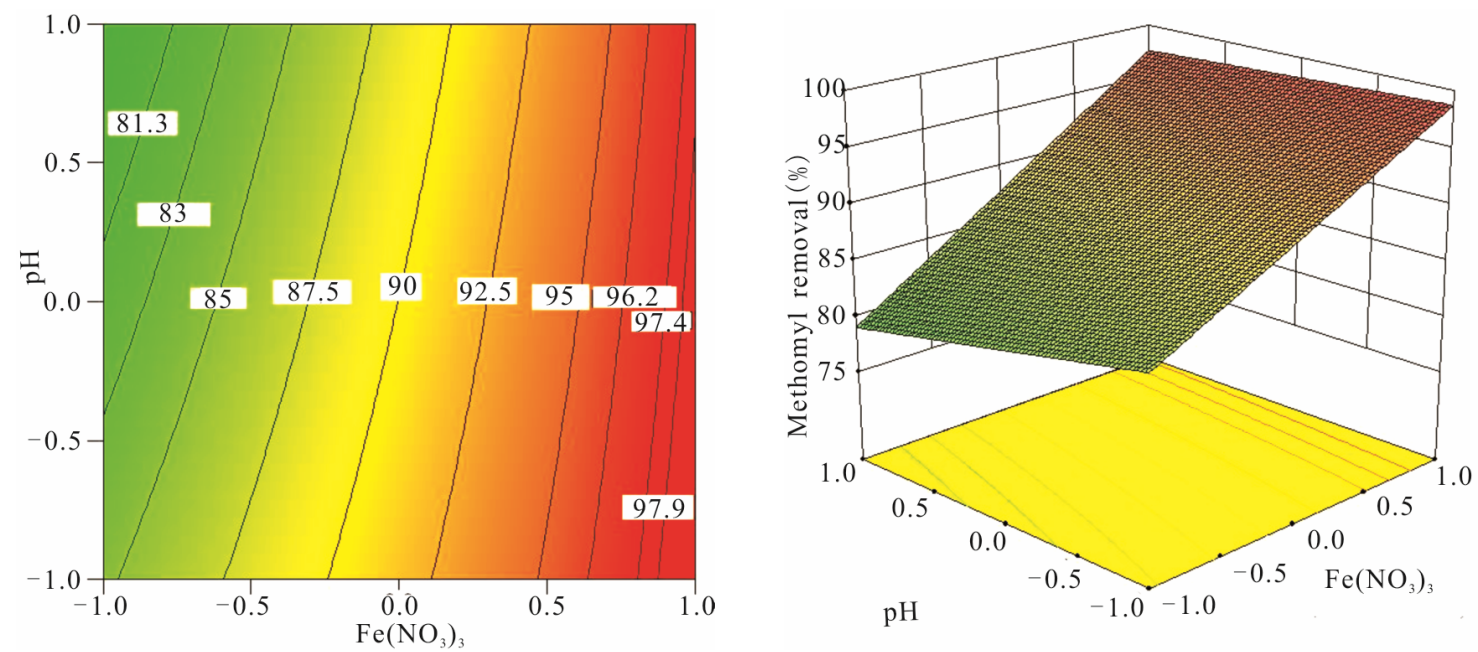

Figure 7. The response surface and contour plot as a function of $\mathrm{Fe}\left(\mathrm{NO}_{3}\right)_{3}$ dosage rate and $\mathrm{pH}$ of methomyl removal at 15 min. 

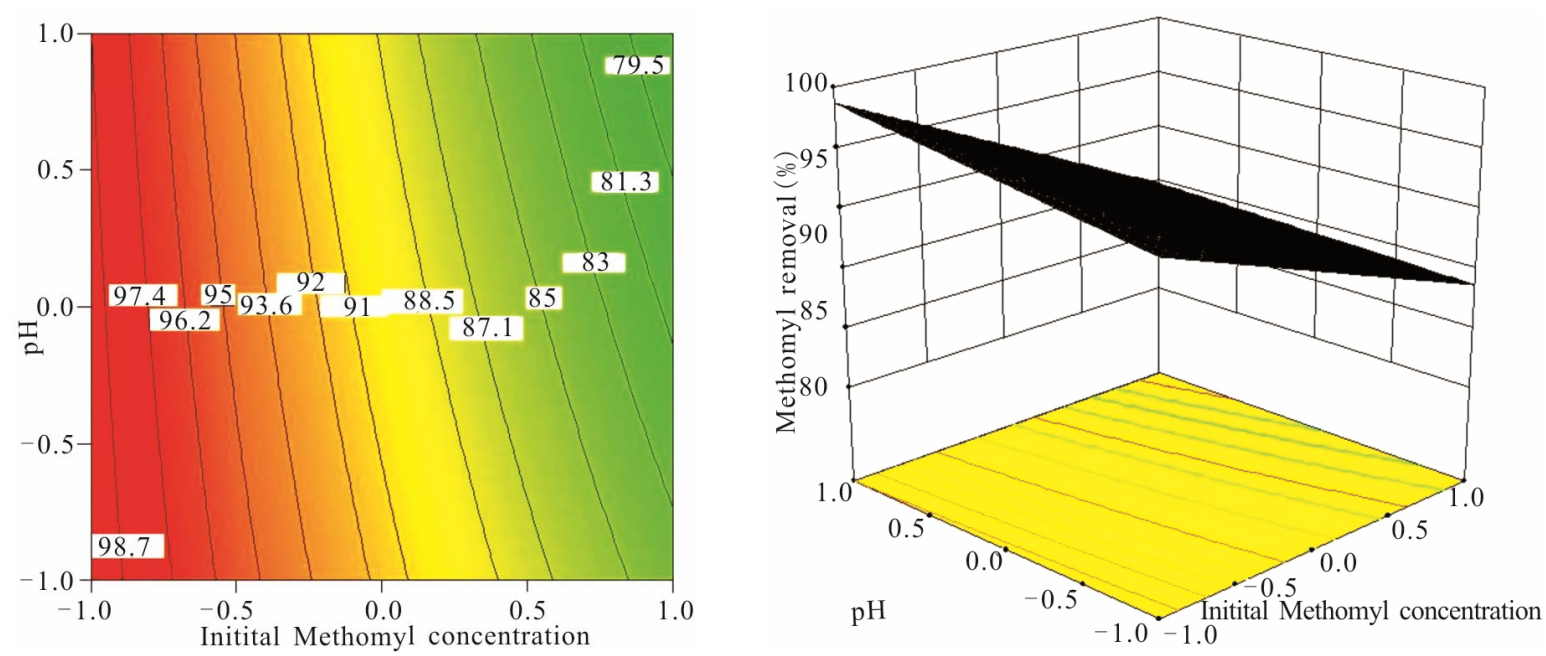

Figure 8. The response surface and contour plot as a function of initial methomyl concentration and pH of methomyl removal at $15 \mathrm{~min}$.

efficiency. The response surface of methomyl removal efficiency gradually increased with increasing $\mathrm{Fe}\left(\mathrm{NO}_{3}\right)_{3}$ concentration from $10^{-4} \mathrm{~mol} \cdot \mathrm{L}^{-1}$ to $5 \times 10^{-4} \mathrm{~mol} \cdot \mathrm{L}^{-1}$. The maximum value of photo-Fenton degradation determined was $100 \%$ at $\mathrm{Fe}\left(\mathrm{NO}_{3}\right)_{3} 5 \times 10^{-4} \mathrm{~mol} \cdot \mathrm{L}^{-1}$ and $6 \times 10^{-5}$ $\mathrm{mol} \cdot \mathrm{L}^{-1}$ methomyl concentration.

The reason is when $\mathrm{Fe}^{2+}$ concentration increased, the catalytic effect also accordingly increased. When the concentration of $\mathrm{Fe}^{2+}$ was higher, a great amount of $\mathrm{Fe}^{3+}$ from the process of $\mathrm{H}_{2} \mathrm{O}_{2}$ decomposition by $\mathrm{Fe}^{2+}$ was easy to exit in the form of $\mathrm{Fe}(\mathrm{OH})^{2+}$ in acidic environment.

Figure 7 shows the effect of $\mathrm{Fe}\left(\mathrm{NO}_{3}\right)_{3}$ concentration and $\mathrm{pH}$ on methomyl removal efficiency. The response surface of methomyl removal efficiency gradually increased with decreasing initial $\mathrm{pH}$ value from 5.4 to 3 . The maximum value of photo-Fenton degradation determined was $98 \%$ at $\mathrm{Fe}\left(\mathrm{NO}_{3}\right)_{3} 5 \times 10^{-4} \mathrm{~mol} \cdot \mathrm{L}^{-1}$ and 3 initial $\mathrm{pH}$ value.

The degradation decreased at $\mathrm{pH}$ values higher than 5.4 , because iron precipitated as hydroxide, which resulted in a reduction in the transmission of the radiation [26]. Additionally, the oxidation potential of hydroxyl radical was known to decrease with increasing $\mathrm{pH}$ [2-7]. Another reason for the inefficient degradation at $\mathrm{pH}>3$ is due to the dissociation and auto-decomposition of $\mathrm{H}_{2} \mathrm{O}_{2}$ [1]. For $\mathrm{pH}$ values below 3 , there action of hydrogen peroxide with $\mathrm{Fe}^{2+}$ is seriously affected causing the reduction in hydroxyl radical production [27].

In Figure 8 the effect of initial methomyl concentration and $\mathrm{pH}$ on methomyl removal efficiency. The response surface of methomyl removal efficiency gradually decreased with increasing initial methomyl concentration from $6 \times 10^{-5} \mathrm{~mol} \cdot \mathrm{L}^{-1}$ to $1.23 \times 10^{-4} \mathrm{~mol} \cdot \mathrm{L}^{-1}$. The maximum value of photo-Fenton degradation determined was $99 \%$ at $6 \times 10^{-5} \mathrm{~mol} \cdot \mathrm{L}^{-1}$ methomyl concentration and 3 initial $\mathrm{pH}$ value.

The maximum photo-Fenton degradation efficiency of methomyl obtained in this study was found to be $100 \%$, corresponding to the operating conditions of $5 \times 10^{-4}$ $\mathrm{mol} \cdot \mathrm{L}^{-1}, 10^{-2} \mathrm{~mol} \cdot \mathrm{L}^{-1}, 6 \times 10^{-5} \mathrm{~mol} \cdot \mathrm{L}^{-1}$ and 3 , respectively, for the $\mathrm{Fe}\left(\mathrm{NO}_{3}\right)_{3}$ concentration, $\mathrm{H}_{2} \mathrm{O}_{2}$ dosage, initial methomyl concentration and $\mathrm{pH}$.

The interaction between $\mathrm{Fe}\left(\mathrm{NO}_{3}\right)_{3}$ concentration and initial methomyl concentration was the most important interaction. However, the interaction between $\mathrm{Fe}\left(\mathrm{NO}_{3}\right)_{3}$ concentration, $\mathrm{H}_{2} \mathrm{O}_{2}$ concentration and $\mathrm{pH}$ was least influencing because photo-Fenton degradation efficiency does not change significantly.

\section{Conclusion}

The work presented here provides support for the degradation of methomyl as a model for environmental contaminant. The experimental design used allows rigorous analysis of the factors influencing methomyl degradation in a photo-Fenton process. The optimum process conditions obtained through a statistical method full factorial experimental design was successfully determined to maximize the methomyl degradation. The model predicted that initial methomyl concentration and $\mathrm{Fe}\left(\mathrm{NO}_{3}\right)_{3}$ has significant effects on photocatalytic methomyl degradation. Maximal methomyl removal efficiency of $100 \%$ was obtained at the optimum conditions as follows: $\mathrm{Fe}\left(\mathrm{NO}_{3}\right)_{3}$ concentration $\left(5 \times 10^{-4} \mathrm{~mol} \cdot \mathrm{L}^{-1}\right), \mathrm{H}_{2} \mathrm{O}_{2}$ concentration $\left(10^{-2} \mathrm{~mol} \cdot \mathrm{L}^{-1}\right)$, methomyl concentration $(6 \times$ $10^{-5} \mathrm{~mol} \cdot \mathrm{L}^{-1}$ ) and initial $\mathrm{pH}$ value (3). The high correlation of the model with the experimental results indicates that RSM analytical procedure could be a general method to describe the similar photo-Fenton system and to predict its behavior. Good agreement between predicted and 
experimental data at the optimum conditions confirms the usefulness of the model.

\section{REFERENCES}

[1] M. I. Badawy, M. Y. Ghaly and T. A. Gad-Allah, "Advanced Oxidation Processes for the Removal of Organophosphorus Pesticides from Wastewater," Desalination, Vol. 194, No. 1-3, 2006, pp. 166-175. doi:10.1016/i.desal.2005.09.027

[2] W. F. Ritter, R. W. Scarborough and A. E. M. Chirnside, "Contamination of Groundwaters by Triazines, Metolachlor, and Alachlor," Journal of Contaminant Hydrology, Vol. 15, No. 1-2, 1994, pp. 73-92. doi:10.1016/0169-7722(94)90011-6

[3] T. J. Strathmann and A. T. Stone, "Reduction of the Carbamate Pesticides Oxamyl and Methomyl by Dissolved $\mathrm{Fe}(\mathrm{II})$ and $\mathrm{Cu}(\mathrm{I})$," Environmental Science and Technology, Vol. 35, No. 12, 2001, pp. 2461-2469. doi:10.1021/es001824j

[4] M. Tamimi, S. Qourzal, A. Assabbane, J.-M. Chovelon, C. Ferronato and Y. Ait-Ichou, "Photocatalytic Degradation of Pesticide Methomyl: Determination of the Reaction Pathway and Identification of Intermediate Products," Photochemical and Photobiological Sciences, Vol. 5, No. 5, 2006, pp. 477-482. doi:10.1039/b517105a

[5] Y. Lin, C. Ferronato, N. Deng, F. Wu and J.-M. Chovelon, "Photocatalytic Degradation of Methylparaben by $\mathrm{TiO}_{2}$ : Multivariable Experimental Design and Mechanism," Applied Catalysis B: Environmental, Vol. 88, No. 1-2, 2009, pp. 32-41. doi:10.1016/j.apcatb.2008.09.026

[6] N. Barka, S. Qourzal, A. Assabbane, A. Nounah and Y. Ait-Ichou, "Photocatalytic Degradation of an Azo Reactive Dye, Reactive Yellow 84, in Water Using an Industrial Titanium Dioxide Coated Media," Arabian Journal of Chemistry, Vol. 3, No. 4, 2010, pp. 279-283. doi:10.1016/j.arabjc.2010.06.016

[7] M. Abdennouri, A. Galadi, N. Barka, M. Baâlala, K. Nohair, M. Elkrati, M. Sadiq and M. Bensitel. "Synthesis, Characterization and Photocatalytic Activity by ParaChlorotoluene Photoxidation of Tin Oxide Films Deposited on Pyrex Glass Substrates," Physical and Chemical News, Vol. 54, No. 7, 2010, pp. 126-130.

[8] D. Keane, S. Basha, K. Nolan, A. Morrissey, M. Oelgemöller and J. M. Tobin, "Photodegradation of Famotidine by Integrated Photocatalytic Adsorbent and Kinetic Study," Catalysis Letters, Vol. 141, No. 2, 2011, pp. 300-308. doi:10.1007/s10562-010-0485-y

[9] N. Barka, S. Qourzal, A. Assabbane, A. Nounah and Y. Ait-Ichou, "Triphenylmethane Dye, Patent Blue V, Photocatalytic Degradation on Supported $\mathrm{TiO}_{2}$ : Kinetics, Mineralization and Reaction Pathway," Chemical Engineering Communications, Vol. 198, No. 10, 2011, pp. 1233-1243. doi:10.1080/00986445.2010.525206

[10] C. S. Chiou, Y. H. Chen, C. T. Chang, C. Y. Chang, J. L. Shie and Y. S. Li, "Photochemical Mineralization of Dinbutyl Phthalate with $\mathrm{H}_{2} \mathrm{O}_{2} / \mathrm{Fe}^{3+}$," Journal of Hazardous Materials, Vol. 135, No. 1-3, 2006, pp. 344-349. doi:10.1016/j.jhazmat.2005.11.072
[11] M. Tamimi, S. Qourzal, N. Barka, A. Assabbane and Y. Aît Ichou, "Methomyl Degradation in Aqueous Solutions by Fenton's Reagent and the Photo-Fenton System," Separation and Purification Technology, Vol. 61, No. 1, 2008, pp. 103-108. doi:10.1016/j.seppur.2007.09.017

[12] F. Torrades, M. Pérez, H. D. Mansilla and J. Peral, "Experimental Design of Fenton and Photo-Fenton Reactions for the Treatment of Cellulose Bleaching Effluents," Chemosphere, Vol. 53, No. 10, 2003, pp. 1211-1220. doi:10.1016/S0045-6535(03)00579-4

[13] P. Kajitvichyanukula, M. C. Lu and A. Jamroensan, "Formaldehyde Degradation in the Presence of Methanol by Photo-Fenton Process," Journal of Environmental Management, Vol. 86, No. 3, 2008, pp. 545-553. doi:10.1016/i.jenvman.2006.12.016

[14] I. B. S. Will, J. E. F. Moraes, A. C. S. C. Teixeira, R. Guardani and C. A. O. Nascimento, "Photo-Fenton Degradation of Wastewater Containing Organic Compounds in Solar Reactors," Separation and Purification Technology, Vol. 34, No. 1-3, 2004, pp. 51-57. doi:10.1016/S1383-5866(03)00174-6

[15] J. Antony and R. K. Roy, "Improving the Process Quality Using Statistical Design of Experiments: A Case Study," Quality Assurance, Vol. 6, No. 2, 1999, pp. 87-95. doi:10.1080/105294199277888

[16] D. C. Montgomery, "Design and Analysis of Experiments: Response Surface Method and Design," John Wiley and Sons, Chichester, 2005.

[17] M. A. Rauf, N. Marzouki and B. K. Kbahti, "Photolytic Decolorization of Rose Bengal by $\mathrm{UV} / \mathrm{H}_{2} \mathrm{O}_{2}$ and Data Optimization Using Response Surface Method," Journal of Hazardous Materials, Vol. 159, No. 2-3, 2008, pp. 602-609. doi:10.1016/j.jhazmat.2008.02.098

[18] I. H. Cho and K. D. Zoh, "Photocatalytic Degradation of Azo Dye (Reactive Red 120) in $\mathrm{TiO}_{2} /$ UV System: Optimization and Modelling Using a Response Surface Methodology (RSM) Based on the Central Composite Design," Dyes and Pigments, Vol. 75, No. 3, 2007, pp. 533-543. doi:10.1016/j.dyepig.2006.06.041

[19] N. Barka, M. Abdennouri, A. Boussaoud, A. Galadi, M. Baâlala, M. Bensitel, A. Sahibed-Dine, K. Nohair and M. Sadiq, "Full Factorial Experimental Design Applied to Oxalic Acid Photocatalytic Degradation in $\mathrm{TiO}_{2}$ Aqueous Suspension," Arabian Journal of Chemistry, 2011. doi:10.1016/j.arabjc.2010.12.015

[20] A. R. Khataee, M. B. Kasiri and L. Alidokht, "Application of Response Surface Methodology in the Optimization of Photocatalytic Removal of Environmental Pollutants Using Nanocatalysts," Environmental Technology, Vol. 32, No. 15, 2011, pp. 1669-1684. doi:10.1080/09593330.2011.597432

[21] H. P. Li, G. Q. Zhao, S. T. Niu and Y. G. Luan, "Technologic Parameter Optimization of Gas Quenching Process Using Response Surface Method," Computational Materials Science, Vol. 38, No. 3, 2007, pp. 561-570. doi:10.1016/j.commatsci.2006.03.014

[22] G. E. P. Box and J. S. Hunter, "Multifactor Experimental Design for Exploring Response Surfaces," Annals of Mathematical Statistics, Vol. 28, No. 1, 1957, pp. 195-241. 
doi:10.1214/aoms/1177707047

[23] R. H. Myers and D. C. Montgomery, "Response Surface Methodology: Process and Product Optimization Using Designed Experiments," John Wiley and Sons, New York, 2002.

[24] J. F. Fu, Y. Q. Zhao and Q. L. Wu, "Optimising Photoelectrocatalytic Oxidation of Fulvic Acid Using Response Surface Methodology," Journal of Hazardous Materials, Vol. 144, No. 1-2, 2007, pp. 499-505. doi:10.1016/j.jhazmat.2006.10.071

[25] K. Ravikumar, S. Krishnan, S. Ramalingam and K. Balu, "Optimization of Process Variables by the Application of
Response Surface Methodology for Dye Removal Using a Novel Adsorbent," Dyes and Pigments, Vol. 72, No. 1, 2007, pp. 66-74. doi:10.1016/j.dyepig.2005.07.018

[26] B. C. Faust and J. Hoigne, "Photolysis of Fe(III)-Hydroxyl Complexes as Sources of $\mathrm{OH}$ Radicals in Clouds, Fog and Rain," Atmospheric Environment, Vol. 24, No. 1, 1990, pp. 79-89. doi:10.1016/0960-1686(90)90443-Q

[27] M. S. Lucas and J. A. Peres, "Decolorization of the Azo Dye Reactive Black 5 by Fenton and Photo-Fenton Oxidation," Dyes and Pigments, Vol. 71, No. 3, 2006, pp. 236-244. doi:10.1016/j.dyepig.2005.07.007 